\title{
EDUCAÇÃO DO INDIVÍdUO PARA O SÉCULO XXI: O RELATÓRIO DELORS COMO REPRESENTAÇÃO DA PERSPECTIVA DA UNESCO
}

\section{EDUCATION OF THE INDIVIDUAL FOR THE XXI CENTURY: THE DELORS REPORT AS REPRESENTING THE UNESCO PERSPECTIVE}

Felipe Augusto Fernandes Borges ${ }^{1}$

\section{RESUMO}

Este trabalho pretende realizar uma análise do Relatório da Comissão Internacional sobre Educação para o século XXI da UNESCO, "Educação: Um tesouro a Descobrir", o conhecido Relatório Delors. Empreendemos para tal um estudo sobre os principais pontos do referido Relatório, demonstrando as concepções de educação e formação expressas pelo mesmo. Aborda-se ainda a centralidade dos princípios dos "quatro pilares da educação" concebidos como fundamentos do projeto educacional preconizado no documento. É abordada também a responsabilização individual do sujeito pelas soluções aos problemas e conflitos do planeta e a desconsideração que se faz das contradições sociais como responsáveis por tais tensões sociais. Nesta análise demonstramos o caráter de responsabilidade da educação para formação do cidadão necessário ao século XXI sob a perspectiva da UNESCO, bem como apontamos para a influência que estas concepções exercem sobre as políticas educacionais elaboradas no Brasil e em outros países.

PALAVRAS-CHAVE: Educação - UNESCO - Relatório Delors - Século XXI.

\begin{abstract}
This work intends to carry out an analysis of the report of the International Commission on education for the twenty-first century UNESCO, "education: a treasure to discover", the wellknown Delors report. Undertake a study on the main points of that report, demonstrating the concepts expressed by education and training. Discusses the centrality of the principles of the "four pillars of education" designed as fundamentals of educational project proposed in the document. Is addressed also the individual accountability of the subject by the solutions to problems and conflicts on the planet and the disregard that makes social contradictions as responsible for such social tensions. This analysis demonstrated the character of the
\end{abstract}


responsibility education for citizens education necessary for the XXI century from the perspective of UNESCO, as well as point to the influence that these conceptions have over educational policies drawn up in Brazil and in other countries.

KEY-WORDS: Education - UNESCO - Delors Report - The XXI Century.

\section{INTRODUÇÃO}

O Relatório da Comissão Internacional sobre Educação para o século XXI da UNESCO, "Educação: Um tesouro a Descobrir", é um importante documento ligado ao campo da educação. Fruto de cerca de três anos de reuniões da referida Comissão presidida por Jacques Delors, o Relatório traz em si ideais e direcionamentos para aquilo que a Comissão considerava como a educação necessária ao século XXI.

Este trabalho pretende apresentar inicialmente o contexto de produção do Relatório Delors, destacando a realidade à qual o mesmo precisava atender, bem como os condicionantes histórico-sociais que se engendraram em sua elaboração.

Pretende-se, ainda, destacar e delinear alguns dos conceitos de educação expressos no documento, a fim de compreender em que sentido estes de imbricam sobre a formação do cidadão desejado para o século XXI. Far-se-á uso contínuo de trechos do próprio Relatório, com intuito de demonstrar como o texto original de articula no processo de apresentação das formas de educação concebidas e desejadas pelo mesmo.

Ainda abordaremos a questão dos "quatro pilares da educação": aprender a conhecer, aprender a fazer, aprender a viver juntos, aprender a viver com os outros e aprender a ser. Faremos tal abordagem, pois consideramos que a compreensão do significado mais aprofundado de cada um dos quatro pilares contribui para a compreensão mais ampla do (também amplo) conceito de educação trazido pelo Relatório.

Cabe ressaltar que, assim como outros documentos internacionais, principalmente aqueles oriundos da UNESCO, o Relatório Delors obteve grande influência na formulação de políticas públicas e agendas para a educação não só no Brasil como em diversos países do mundo. Sendo assim, este estudo justifica-se pelo fato de que compreender a educação abordada por Delors significa obter subsídios para uma mais aprofundada análise das influências externas que por diversos momentos direcionam a formulação de programas 
educacionais nos países. Aquilo que muitas vezes parece ser uma agenda própria, nacional, atendendo aos interesses de determinada nação, pode (muito provavelmente) ser na verdade fruto direto de uma ou mais diretrizes internacionais que motivam sua formulação.

Dessa forma, cabe ao pesquisador não desavisado analisar minuciosamente as políticas e agendas e assim compreender não apenas o sentido prático das mesmas, mas, ainda, o âmago mais profundo das questões levantadas. Ao analisar mais uma vez o Relatório Delors, pretendemos de alguma forma contribuir para o enriquecimento desses processos de análise das políticas educacionais.

\title{
O RELATÓRIO DELORS
}

O Relatório para a UNESCO da Comissão Internacional sobre Educação para o século XXI, intitulado como "Educação: Um tesouro a Descobrir" é um documento amplamente conhecido, tendo, desde sua publicação, alcançado destaque nos meios educacionais. Largamente conhecido apenas como Relatório Delors, este documento serviu como parâmetro para elaboração de várias agendas educacionais no mundo todo.

A fim de compreendermos de melhor forma os ideais e objetivos expressos no documento e, consequentemente, seus desdobramentos na formulação de agendas para o campo educacional, pensamos ser necessário inicialmente discorrer a respeito das condições históricas em que se deu a elaboração do Relatório. Segundo Vieira e Sforni (s/d, p.02)

\begin{abstract}
As mudanças ocorridas no setor produtivo sempre desencadearam (e continuam desencadeando) mudanças tanto na esfera produtiva e econômica como na educacional, e influenciam decisivamente o modo de ser dos homens, sua forma de pensar, sentir, agir e se relacionar com outros homens. Por isso, para compreender os objetivos educacionais propostos nos documentos educacionais é necessário compreender as exigências impostas pela organização do processo produtivo na sociedade capitalista contemporânea - o sistema de acumulação flexível.
\end{abstract}

O Relatório Delors emerge em meio a um contexto que lhe é próprio: na década de 90, em meio à crise do modelo de produção e do capital, são feitas várias reestruturações econômicas e sociais que vão, por fim, desencadear-se no campo da educação.

A crise do modelo de produção, advinda da grande acumulação de estoques, leva o capitalismo a mais uma de suas crises e a uma consequente necessidade de mudança. Os 
modelos de produção Taylorista-fordista acabaram por levar a um acúmulo desnecessário de mercadoria que por sua vez gerava quedas expressivas nas taxas de lucro. Assim, houve a progressiva substituição destes pelo Toyotismo, um modelo de produção diferenciado, com maior ênfase no planejamento e na atividade intelectual do trabalhador.

O modelo Toyotista presume maior participação intelectual do trabalhador como também maior conhecimento do processo de produção como um todo. Dessa forma, compreendemos também que o trabalhador do modelo anterior precisava readequar-se a fim de satisfazer as necessidades do novo modelo. Para além disso, não só o trabalhador mas também o próprio sistema de administração pública precisava reformular-se, com vistas a atender à manutenção do sistema: é o que hoje chamamos de Reforma do Estado (KUENZER, 2005).

Nesse âmbito, compreendemos que se faziam necessários ajustes também na esfera educacional, uma vez que a educação também era entendida como uma instituição social vinculada ao Estado, portanto, pública. Essas mudanças deveriam, em sua base, atender a duas características principais: primeiramente ao ajuste da administração escolar em acompanhamento da administração geral e da própria reformulação da administração pública. Uma segunda característica, mais relevante no caso da análise do Relatório Delors é o ajuste da educação a fim de formar o sujeito necessário ao novo modelo de produção, ou seja, atender às novas expectativas sociais de formação.

O organizador do Relatório, Jacques Delors é um francês, nascido na cidade de Paris, em 20 de Julho de 1925. Cabe destacar que Delors foi ministro da Economia e Finanças da França e presidente da Comissão Europeia entre 1985 e 1995 (RIZO, 2010).

No ano de 1993, foi criada pela UNESCO uma "Comissão Internacional de Educação para o século 21", cuja presidência foi exercida por Jacques Delors. A comissão tinha por objetivo principal fomentar reflexões e buscar soluções para aquilo que consideravam "os desafios" que a educação enfrentaria frente ao novo século. Considerando o momento de reestruturação financeira e de reelaborações do papel do Estado, ocorrida na década de 90 como também o crescente discurso que elevava a educação como motor de desenvolvimento das nações,no centro dos debates da Comissão estava a necessidade de viabilizar uma formação ampla, que realmente desenvolvesse nos indivíduos as qualidades necessáriasao homem do ao novo século. Rizo corrobora a afirmação acima mostrando que 
Na década de 1990, grande parte das preocupações e atitudes mundiais estava voltada para a construção de perspectivas, tendo em vista a ansiedade gerada pela chegada de um novo século. O campo educacional não se afastou desse comportamento. Políticas de alfabetização e de aumento da escolaridade, em vários países, pretendiam contribuir para que as metas da Conferência Mundial de Educação de 1990, em Jomtien, Educação para todos, fossem alcançadas. Ao mesmo tempo, estratégias internacionais eram concebidas para se estabelecer um tipo de educação capaz de moldar crianças e jovens que se tornariam os adultos de uma nova era. (RIZO, 2010, p.55, grifo da autora)

Podemos assim compreender que o Relatório resultante das reuniões e discussões da Comissão expressa muito mais do que aquilo que podemos ler em suas linhas. Há, na própria formação do discurso um ideal de homem a ser formado, a fim de atender à necessidade do mundo do século XXI: global, total e dinâmico.Além disso, o Relatório abrange também uma descrição dos diversos problemas pelos quais o mundo estaria passando no romper do novo século. Segundo Oliveira, Moura e Silva (2012, p.403),

[...] o documento também traz os problemas socioeconômicos e socioculturais, trazendo uma enorme desilusão à população mundial, revelando dados drásticos sobre a miséria, o desemprego e a exclusão social. Mas o marco mais bonito do relatório são as belas palavras que nos diz que a educação deve ser ao longo da vida, que os povos devem ser solidários, que é preciso ter tolerância e respeito mútuo, esses são valores essenciais para uma Educação digna e justa.

Ao tratar sobre educação, Delors e a Comissão têm em vista processos muito mais amplos e subjetivos, os quais extrapolam os limites da educação formal. A visão e a necessidade do contexto da década de 90, quando da elaboração do documento, apontam para uma formação total e subjetiva, que faça do indivíduo um cidadão do mundo, alguém que assuma, juntamente com as nações, responsabilidades individuais e coletivas para o bem da sociedade e do planeta.

Fundamentalmente, a UNESCO estará servindo a paz e a compreensão entre os homens, ao valorizar a educação como espírito de concórdia, de emergência de um querer viver juntos como militantes da nossa aldeia global que há que pensar e organizar, para bem das gerações futuras. Deste modo, estará contribuindo para uma cultura da paz. (DELORS, 1998, p.31)

Tal resgate, apesar de talvez ser um tanto óbvio, é necessário, para que não se perca de vista a historicidade do documento em questão. Para além de um emaranhado de 
objetivos ou diretrizes, o Relatório constitui-se num documento expressão de um desejo, de um anseio advindo do mundo em globalização. Cabe ressaltar que o Relatório "Surgiu no Brasil apenas no ano de 1998, apresentado pelo então Ministro da Educação e Cultura, Paulo Renato Costa Souza", e que desde então "realçou-se a importância do documento para que o país cumprisse as metas" (OLIVEIRA, MOURA e SILVA, 2012, p. 402-403).

Tendo em vista o acima exposto, podemos partir para uma análise de alguns pontos interessantes do Relatório, a fim de apontar algumas de suas influências mais práticas na formulação de agendas e políticas públicas paraa educação, não apenas no Brasil, mas também em diversos outros países do mundo.

\section{A EDUCAÇÃO NO RELATÓRIO DELORS}

A redação do Relatório Delors enfatiza, desde seu início e por toda sua extensão, a necessidade da educação ampla, como meio de formação do "cidadão do mundo" (DELORS, 1998, p.14). A educação como tema central do Relatório carrega consigo os significados que aquela comissão, sob a ideologia da UNESCO, aplica sobre a mesma. Dessa forma, nosso objetivo neste é esmiuçar trechos (por nós considerados como chaves) a fim de compreender quais relações e significados se colocam junto à educação no Relatório. Com relação já às alusões iniciais para com a educação, lemos no próprio Relatório que:

Ante os múltiplos desafios do futuro, a educação surge como um trunfo indispensável à humanidade na sua construção dos ideais da paz, da liberdade e da justiça social. Ao terminar os seus trabalhos a Comissão faz, pois, questão de afirmar a sua fé no papel essencial da educação no desenvolvimento contínuo, tanto das pessoas como das sociedades. Não como um "remédio milagroso", não como um "abre-te sésamo" de um mundo que atingiu a realização de todos os seus ideais mas, entre outros caminhos e para além deles, como uma via que conduza a um desenvolvimento humano mais harmonioso, mais autêntico, de modo a fazer recuar a pobreza, a exclusão social, as incompreensões, as opressões, as guerras...(DELORS, 1998, p. 11, grifos nossos)

Pode-se observar, principalmente nos adjetivos que acima destacamos as qualidades e expectativas voltadas sobre a educação, já no início da escrita do Relatório: indispensável, essencial, contínuo, harmonioso e autêntico. Esses adjetivos, combinados, sugerem aquilo que se espera do homem para o século XXI, capaz de atender as necessidades 
da sociedade e contribuir para aquilo que se deduz como o crescimento (desenvolvimento) harmonioso da mesma.

O Relatório destaca os desafios do novo século, apontado para um grande desequilíbrio entre países ricos e países pobres, além do aumento da pobreza, o desemprego ainda muito forte em diversas nações do mundo e "fraturas profundas" entre os diferentes grupos sociais. Novamente nas palavras do Relatório,

\begin{abstract}
Desde sempre, as sociedades foram abaladas por conflitos suscetíveis de, nos casos extremos, pôr em perigo a sua coesão. Hoje, contudo, não se pode deixar de dar importância a um conjunto de fenômenos que, na maior parte dos países do mundo, surgem como outros tantos índices de uma crise aguda das relações sociais.

Uma primeira verificação relaciona-se com o agravamento das desigualdades, ligado ao aumento dos fenômenos de pobreza e de exclusão. Não se trata, apenas, das disparidades já mencionadas entre países ou regiões do mundo, mas sim de fraturas profundas entre grupos sociais, tanto no interior dos países desenvolvidos como no dos países em desenvolvimento. A Cúpula Mundial para o Desenvolvimento Social realizada em Copenhague de 6 a 12 de março de 1995 traçou um quadro alarmante da situação social atual, recordando em particular que "no mundo, mais de um bilhão de seres humanos vivem numa pobreza abjeta, passando a maior parte deles fome todos os dias", e que "mais de 120 milhões de pessoas no mundo estão oficialmente no desemprego e muitas mais ainda no subemprego". (DELORS, 1998, p. 52)
\end{abstract}

Em decorrência de todos esses problemas estruturais que o relator cita no trecho, aponta-se para o aumento das migrações internacionais, assinalando principalmente o grande número de migrações ilegais, em que pessoas de países em crise tentam fugir de sua realidade buscando melhores locais para viver e ainda melhores oportunidades de sobrevivência. Tais situações apenas contribuiriam, segundo o Relatório, para o maior agravamento das tensões ao redor do mundo.

Dessa forma, inicialmente destacamos a ideia da educação como ferramenta plausível no combate de tais tensões sociais, ou seja, a educação seria uma forma de conciliar essas tensões, formando um cidadão capaz de superar as dificuldades próprias do seu local de vida, sem a necessidade de "migrar" para isso. Mais do que mudar-se de um lugar para outro em busca de melhores condições, o Relatório propõe que sejam formadas pessoas capazes de mudar sua própria realidade, superar as próprias dificuldades e criar suas próprias oportunidades.

Assim, vemos a educação ser tratada como forma de minimizar as tensões sociais, como forma ainda de conciliar conflitos. Destaque-se que o relatório sugere em suas entrelinhas uma educação não essencialmente como "remédio" para os problemas e tensões 
sociais, mas também como um artigo de prevenção das mesmas, pois compreende-se que o "sujeito Delors" (RIZO, 2010, p.80) é alguém já preparado para lidar com tais situações. O "sujeito Delors" não necessita dos conflitos para sobreviver, pelo contrário, ele é pela educação preparado para superar a si mesmo, suas dificuldades e as dificuldades da sociedade em que está inserido, contribuindo individualmente para resolução/harmonização dos problemas locais e globais. Nesse ponto, a redação do Relatório foi bem clara ao mostrar a quem essa tarefa cabe diretamente: "Cabe à educação a nobre tarefa de despertar em todos, segundo as tradições e convicções de cada um, respeitando inteiramente o pluralismo, esta elevação do pensamento e do espírito para o universal e para uma espécie de superação de si mesmo" (DELORS, 1998, p. 15-16).

No processo de inovações, de mudanças, próprios do século XXI, a educação que promove a "superação de si mesmo" não deve estagnar, não pode ser uma formação que tem início e fim, mas prega-se ao contrário a educação contínua, uma formação que durante toda a vida atualiza o sujeito a fim de que o mesmo acompanhe os processos de mudanças e alterações do mundo e da sociedade.

Assim, uma segunda ideia aqui destacada é a da educação para toda a vida. Levando em consideração todas as modificações da sociedade, a tecnologia em contínuo e rápido desenvolvimento, as diferentes exigências do mundo do trabalho, as diversidades em franco crescimento e todas as demais situações de novidade que exigem a adaptação do sujeito,

[...] parece impor-se, cada vez mais, o conceito de educação ao longo de toda a vida, dadas as vantagens que oferece em matéria de flexibilidade, diversidade e acessibilidade no tempo e no espaço. É a idéia de educação permanente que deve ser repensada e ampliada. É que, além das necessárias adaptações relacionadas com as alterações da vida profissional, ela deve ser encarada como uma construção contínua da pessoa humana, dos seus saberes e aptidões, da sua capacidade de discernir e agir. Deve levar cada um a tomar consciência de si próprio e do meio ambiente que $\mathrm{o}$ rodeia, e a desempenhar o papel social que lhe cabe enquanto trabalhador e cidadão. (DELORS, 1998, p. 18)

A educação, assim concebida, é considerada ainda com mais veemência "uma das chaves de acesso ao século XXI" (DELORS, 1998, p.19). O conceito de "chave", aqui utilizado, denota que a educação é considerada como o bem que fará com que o sujeito efetivamente entre no século XXI. Cabe destacar que, nessa perspectiva, aquele que estiver à margem dessa educação estará por consequência à margem da sociedade e à margem do século XXI. Entende-se aqui que esta formação ao longo da vida é o único meio de preparar o 
homem para as inovações que sucessivamente se apresentarão a ele. É o meio de criar, originar, produzir, a tão sonhada adaptação, harmonia, e até mesmo a empregabilidade do sujeito. A educação trazida ao palco pelo Relatório é o meio de produzir o século XXI: ao mesmo tempo em que as inovações exigem esta educação daqueles que as forem operar, a própria educação aqui apresentada será responsável por desenvolver mais tecnologias, sendo então responsável tanto pelo princípio quanto pela finalidade das tecnologias em desenvolvimento.

A educação também é chamada à tarefa da compreensão. Segundo Delors, é papel da educação também formar o indivíduo compreensivo: de si mesmo e do outro. O indivíduo deve reconhecer e valorizar suas raízes, seu local, sua sociedade, mas tudo isso sem perder de vista as outras culturas, os outros lugares, as diversidades. O sujeito aqui descrito deve ser capaz de compreender o outro e sua cultura, valorizá-lo e respeitá-lo para a existência de um mundo mais solidário.

A educação tem, pois, uma especial responsabilidade na edificação de um mundo mais solidário, e a Comissão pensa que as políticas de educação devem deixar transparecer, de modo bem claro, essa responsabilidade. É, de algum modo, um novo humanismo que a educação deve ajudar a nascer, com um componente ético essencial, e um grande espaço dedicado ao conhecimento das culturas e dos valores espirituais das diferentes civilizações e ao respeito pelos mesmos para contrabalançar uma globalização em que apenas se observam aspectos econômicos ou tecnicistas. O sentimento de partilhar valores e um destino comuns constitui, em última análise, o fundamento de todo e qualquer projeto de cooperação internacional. (DELORS, 1998, p.49)

Para contrabalancear as relações econômicas e tecnológicas em que o mundo e a globalização se inserem e se relacionam, a educação deve resgatar o caráter humano da convivência social, fortalecer os vínculos entre as pessoas, e contribuir para a humanização das relações. É, de certa forma, um meio de fugir do economicismo (ao menos no discurso), dando a ideia de humanidade, amizade e paz nas relações sociais, mesmo quando estas envolverem os processos econômicos e tecnológicos já mencionados. Na sequência do trecho anterior Delors afirma que:

Em todo o mundo, a educação, sob as suas diversas formas, tem por missão criar, entre as pessoas, vínculos sociais que tenham a sua origem em referências comuns. Os meios utilizados abrangem as culturas e as circunstâncias mais diversas; em todos os casos, a educação tem como objetivo essencial o desenvolvimento do ser 
humano na sua dimensão social. Define-se como veículo de culturas e de valores, como construção de um espaço de socialização, e como cadinho de preparação de um projeto comum. (DELORS, 1998, p.51)

Uma dupla jornada está posta: a educação que forma para a tecnologia, a inovação e o emprego, mas, também, a educação que forma para o convívio, para a socialização, o intercâmbio de culturas, porém sempre visando a preparação de um dito "projeto comum". Pergunta-se: que "projeto" seria esse? A que projeto, a que objetivo o Relatório se refere todas as vezes a que menciona essa expressão?

Entendemos que o projeto mencionado por Delors é, fatalmente, o projeto de sociedade da UNESCO: desenvolvimento econômico, intelectual, social, engendrado numa desejada harmonia entre os sujeitos, os grupos sociais, os interesses coletivos e os privados. Torna-se um tanto difícil (a nosso ver) imaginar uma realidade em que, todos os interesses, os mais diversos possíveis e, às vezes, mesmo antagônicos, possam harmonizar-se tranquilamente sob a esfera da compreensão e da paz construídas por um bom projeto educacional. Porém, essa é a ideia trazida pelo documento em questão, portanto considerada por este de possível alcance.

Nesse sentido, o Relatório caminha ainda para a responsabilização do sujeito por seus atos, tanto individuais quanto também coletivos. O sujeito, alvo da educação Delors, passa a ser individualmente responsável pelo sucesso do projeto da coletividade. Este sujeito a ser formado deve ser reflexivo, autônomo, capaz de intervir intencionalmente no devir social, sendo responsável pelo seu sucesso enquanto individual, assim como pelo sucesso de seu grupo, e, ainda, pelo futuro do próprio planeta, no que diz respeito ao humano e mesmo ao ambiental. Em um trecho que abarca os valores que a educação deve cultivar para formação de uma "ética global" essa ideia de responsabilização individual fica bem clara quando se apresenta a "solicitude para com o outro". Esse, segundo o Relatório seria um

[...] valor decisivo para a educaçãode amanhã e manifestação intrínseca de compaixão humana, deque se deve dar provas não só em relação aos membros da própriafamília e aos colegas, mas também em relação a todos os desfavorecidos, doentes, pobres ou em situação de inferioridade, e queanda a par como cuidado pelo bem-estar da humanidade e donosso planeta. (DELORS, 1998, p.264, grifo nosso) 
A responsabilização do indivíduo extrapola os limites do local, e este é chamado a intervir com solidariedade não só ao próximo de caráter humano, mas a exercer tal solidariedade com a própria estrutura planetária, enquanto moradia de todos os seres humanos. Perde-se de vista, aqui, toda e qualquer interferência do grande capital sobre o "futuro do planeta": as indústrias, os latifúndios, as grandes criações de gado, os desrespeitos aos códigos florestais ao redor do mundo, nada disso importa, pois o indivíduo, justa e magicamente em sua individualidade é que vai se responsabilizar por cuidar do planeta em que vive com seus iguais.

Além de tudo isso, a educação também deve fazer do sujeito um indivíduo crítico e empreendedor, que, mesmo cuidando do futuro da sociedade e do planeta ainda pode trabalhar pelo desenvolvimento econômico e social, sempre levando em conta o caráter sustentável de suas ações. O crescimento dos países em desenvolvimento é encorajado, sabendo que os projetos educacionais devem fomentar a capacidade criativa de cada um, fazendo com que haja cada vez mais empregos, mais oportunidades de crescimento e sucesso profissional a que os diferentes indivíduos tenham acesso. Para isso,

O princípio geral de ação que deve presidir a esta perspectivade um desenvolvimento baseado na participação responsável de todos os membros da sociedade é o do incitamento à iniciativa, ao trabalho em equipe, as sinergias, mas também ao auto-emprego e ao espírito empreendedor: é preciso ativar os recursos de cada país, mobilizar os saberes e os agentes locais, com vista à criação de novas atividades que afastem os malefícios do desemprego tecnológico. Nos países em desenvolvimento esta é a melhor via de conseguir e alimentar processos de desenvolvimento endógeno. Os elementos da estratégia educativa devem, pois, ser concebidos de uma forma coordenada e complementar, tendo por base comum a busca de um tipo de ensino que, também, se adapte às circunstâncias locais. (DELORS, 1998, p.83)

Vimos por meio do destaque de algumas concepções de educação constantes no Relatório, que o mesmo varia, de uma concepção inicialmente ampliada para, posteriormente, afunilar os objetivos da mesma até que se chegue à responsabilização individual de cada sujeito para sucesso do projeto coletivo. A educação é concebida como ferramenta que possibilita ao sujeito ser crítico, compreender a realidade e as dificuldades locais e globais. Mas não apenas isso, a educação constante no Relatório é responsável por subsidiar a ação do sujeito sobre si e sobre seu meio. É a educação que, na visão da UNESCO, vai preparar o sujeito para as relações sociais, humanas, econômicas e tecnológicas do século XXI. Para 
tanto, estrutura o Relatório aquilo que define como "quatro pilares da educação", tratado posteriormente por este trabalho.

\section{OS “QUATRO PILARES”}

A fim de estruturar suas propostas de educação para o século XXI, o Relatório Delors traz em seu texto as diretrizes daquilo que considera serem os quatro pilares da educação, a saber: aprender a conhecer, aprender a fazer, aprender a viver juntos, aprender a viver com os outros e aprender a ser. Por meio destes pilares é que, segundo o documento, os projetos de educação nos países devem guiar-se para alcançar os objetivos educacionais esperados.

Quando nos atentamos para a terminologia usada, já podemos ter uma ideia inicial do que esses pilares representam na ideologia do relatório. A ideia de "pilar" remete-nos a compreensão de um termo semelhante a "sustentação", a parte principal de uma obra, sem a qual todo o restante desaba. Portanto, a educação do Relatório Delors está fundamentada em cada um desses quatro "aprenderes": a educação é assim considerada uma obra, algo a ser erguido, levantado, construído. A UNESCO, por sua parte, lança os pilares, os fundamentos dessa obra, os quais devem ser usados pelos países que continuarão a construção, fundamentados sempre nos pilares já lançados. Assim, os projetos educacionais dos países devem dar ênfase a essas formas de aprendizagem que se constituirão, em síntese, como os meios mais necessários ao sucesso dos mesmos, obviamente, segundo aquilo que é preconizado pelo relatório.

Cada um dos pilares tem uma ligação direta com uma forma de ser/estar/comportar que se espera do cidadão do século XXI. São princípios norteadores propostos para a formação não só intelectual, mas, também, moral e ética dos sujeitos alvo dessa educação. Dessa forma, os pilares são divididos entre os princípios mais práticos (intelectuais) e aqueles mais subjetivos, que dizem respeito principalmente à harmonia na convivência e na cooperação mútua dos indivíduos. Discorrendo inicialmente sobre tais pilares, o Relatório nos mostra que:

Para poder dar resposta ao conjunto das suas missões, a educação deve organizar-se em torno de quatro aprendizagens fundamentais que, ao longo de toda a vida, serão 
de algum modo para cada indivíduo, os pilares do conhecimento: aprender a conhecer, isto é adquirir os instrumentos da compreensão; aprender a fazer, para poder agir sobre o meio envolvente; aprender a viver juntos, a fim de participar e cooperar com os outros em todas as atividades humanas; finalmente aprender a ser, via essencial que integra as três precedentes. É claro que estas quatro vias do saber constituem apenas uma, dado que existem entre elas múltiplos pontos de contato, de relacionamento e de permuta. (DELORS, 1998, p. 89-90, grifos do autor)

Cada um desses pilares traz consigo um significado próprio, uma diretriz para aprendizado e desenvolvimento do indivíduo como um todo. A organização do Relatório, não equivocadamente, traz em primeiro lugar, o pilar do aprender a conhecer. Este princípio torna-se necessário por ser a abertura a todos os demais. Segundo o relatório, a educação deve primeiramente instrumentalizar o indivíduo de todas as capacidades necessárias à compreensão do mundo, dos conteúdos escolares e/ou não-escolares e da sociedade em que vive e relaciona-se. $\mathrm{O}$ aprender a conhecer relaciona-se a uma perspectiva mais intelectual, à responsabilidade da educação de não apenas ensinar seus conteúdos e valores, mas, além disso, ensinar como aprender e apreender tais conteúdos. Nesse sentido, a educação se torna, na perspectiva do Relatório, a responsável pelo início e ainda pela finalidade da educação do cidadão: deve proporcionar os conhecimentos, mas também os subsídios para que o indivíduo possa ter pleno acesso a este.

Aprender para conhecer supõe, antes tudo, aprender a aprender, exercitando a atenção, a memória e o pensamento. Desde a infância, sobretudo nas sociedades dominadas pela imagem televisiva, o jovem deve aprender a prestar atenção às coisas e às pessoas. A sucessão muito rápida de informações mediatizadas, o "zapping" tão freqüente, prejudicam de fato o processo de descoberta, que implica duração e aprofundamento da apreensão. Esta aprendizagem da atenção pode revestir formas diversas e tirar partido de várias ocasiões da vida (jogos, estágios em empresas viagens, trabalhos práticos de ciências...). (DELORS, 1998, p. 92)

Após o aprender a conhecer, ou seja, aprender a utilizar os meios que levam ao conhecimento da cultura, de si e do mundo, haverá de se atentar para o aprender a fazer. Parte mais prática dos pilares, o aprender a fazer está relacionado ao emprego dos conhecimentos proporcionados pelo aprender a conhecer. É uma dimensão estreitamente ligada à formação profissional. Nesse ponto, o Relatório discute sobre como preparar um aluno para um mercado de trabalho cada vez mais dinâmico, mutável e tecnológico. Em contrapartida, e mesmo considerando todas estas variáveis, Delors defende a educação como formadora para esta realidade, como única forma de proporcionar a profissionalização necessária às mudanças 
intempestivas do novo século. A definição do pilar implica ainda nas capacidades necessárias ao trabalho em grupo:

- Aprender a fazer, a fim de adquirir, não somente uma qualificação profissional mas, de uma maneira mais ampla, competências que tornem a pessoa apta a enfrentar numerosas situações e a trabalhar em equipe. Mas também aprender a fazer, no âmbito das diversas experiências sociais ou de trabalho que se oferecem aos jovens e adolescentes, quer espontaneamente, fruto do contexto local ou nacional, quer formalmente, graças ao desenvolvimento do ensino alternado com o trabalho. (DELORS, 1998, p. 101)

O aprender a fazer tem a conotação de tornar o indivíduo apto, pronto ao trabalho, à empregabilidade, às mudanças do mundo do trabalho e ainda à cooperação mútua entre os atores sociais envolvidos no processo. É o ato de preparar o sujeito toda e qualquer situação adversa que a ele se apresente.

Na continuidade da ideia de cooperação já apresentado no aprender a fazer, há um pilar exclusivo para tratar a esse respeito. A sociabilidade, a articulação entre os sujeitos, a harmonia e a solidariedade são sintetizados e apresentados no princípio do aprender a viver juntos. Esse pilar se coloca como opção não somente à solidariedade e cooperação entre as sociedades locais, mas substancialmente também como convivência harmoniosa entre as diferentes sociedades.

Aqui, por consequência, estão englobadas as discussões sobre diversidade cultural, relações étnico-raciais, de gênero, de nacionalidade e todas as demais diferenças que, ao contrário de representarem um fator excludente na relação entre os diferentes devem, segundo aquilo que é demonstrado na redação do documento, ser um fator de união cooperativa e ainda de intercâmbio cultural entre os sujeitos. Aprender a viver juntos é, além de tudo, aprender a viver participando com "os outros" em todas as atividades humanas. Sabese que tal conscientização não é tarefa fácil, pois já em sua introdução o Relatório perguntase: "Mas como aprender a viver juntos nesta "aldeia global", se não somos capazes de viver nas comunidades naturais a que pertencemos: nação, região, cidade, aldeia, vizinhança?” (DELORS, 1998, p.14).

Ainda assim, compreendendo os limites ou mesmo empecilhos existentes no desenvolvimento de um aprender a viver juntos, Delors ainda remete à educação mais essa responsabilidade. As barreiras ao intercâmbio cultural e mesmo à convivência harmoniosa dentro da própria "aldeia local" devem ser trabalhadas e diminuídas (se não extintas) pelo 
trabalho da educação. O "sujeito Delors" tem, necessariamente, que ser formado para viver junto, para cooperar, trabalhar em equipe, operacionalizar bem suas habilidades principalmente em parceria com outros indivíduos e grupos de trabalho. Sendo assim, o Relatório delimita o papel da educação, destacando em seu próprio texto tudo aquilo que acima expomos:

\begin{abstract}
A educação tem por missão, por um lado, transmitir conhecimentos sobre a diversidade da espécie humana e, por outro, levar as pessoas a tomar consciência das semelhanças e da interdependência entre todos os seres humanos do planeta. Desde tenraidade a escola deve, pois, aproveitar todas as ocasiões para esta dupla aprendizagem. Algumas disciplinas estão mais adaptadas a este fim, em particular a geografia humana a partir do ensino básico e as línguas e literaturas estrangeiras mais tarde.

Passando à descoberta do outro, necessariamente, pela descoberta de si mesmo, e por dar à criança e ao adolescente uma visão ajustada do mundo, a educação, seja ela dada pela família, pela comunidade ou pela escola, deve antes de mais ajudá-los a descobrirem-se a si mesmos. Só então poderão, verdadeiramente, pôr-seno lugar dos outros e compreender as suas reações. Desenvolver esta atitude de empatia, na escola, é muito útil para os comportamentos sociais ao longo de toda a vida. (DELORS, 1998, p. 97-98)
\end{abstract}

Como último pilar, porém obviamente não menos importante, encontramos no documento o aprender a ser. Esse pilar/princípio é concebido como a via de integração de todas as anteriores. Aprender a ser seria, total e essencialmente, a formação de uma chamada criticidade do sujeito. A capacidade autônoma de decidir sobre os diferentes assuntos e situações do cotidiano, sendo o sujeito, por meio das capacidades preconizadas nesse princípio, plenamente capaz de executar, por si próprio, todasas tarefas e obrigações anteriormente citadas. Cabe ainda lembrar que essas capacidades, segundo o Relatório, devem estender-se ao longo de toda sua vida. Assim,

Todo o ser humano deve ser preparado, especialmente graças à educação que recebe na juventude, para elaborar pensamentos autônomos e críticos e para formular os seus próprios juízos de valor, de modo a poder decidir, por si mesmo, como agir nas diferentes circunstâncias da vida. (DELORS, 1998, p.99)

Vejamos que fica bem claro na redação de Delors que a capacidade autônoma de tomada de decisão pelo indivíduo deve ser desenvolvida "graças à educação que recebe na juventude". Nessa perspectiva, os projetos de educação dos países, orientando-se nesse documento (expressão também das concepções da UNESCO) deveriam atentar-se para formar 
no sujeito não só a compreensão e a posse de conteúdos e conhecimentos, mas essencialmente também as capacidades subjetivas necessárias a aplicar esses conteúdos em seu dia-a-dia, além das capacidades de autonomia, criticidade, juízos de valor e outras características do aprender a ser.

Podemos observar, por meio da compreensão de cada um daqueles apresentados "quatro pilares" da educação no Relatório Delors, que esses princípios são norteados para uma suposta formação geral, completa, desejada para o cidadão do mundo, o homem do século XXI. Compreendemos que, por meio da elaboração dos quatro pilares, o Relatório confere à educação total responsabilidade pelas mais diferentes instâncias formação humana: desde as capacidades de recebimento e compreensão de informações (aprender a conhecer), passando pelas qualificações técnicas de empregabilidade e trabalho (aprender a fazer), até a convivência e companheirismo (aprender a viver juntos) terminando num misto de todos os demais, na formação intrapessoal do indivíduo (aprender a ser). Destarte, compreendemos que a perspectiva construída para a educação em Delors é fortemente abrangente, de forma que o retorno esperado dessa também é amplo.

\section{CONSIDERAÇÕES FINAIS}

Cabe nesse momento ressaltar mais uma vez que a educação, assim como relatórios, tratados ou documentos que dela se ocupem só podem ser compreendidos se analisados em consonância com o momento histórico em que são produzidos. Todos estes fatores devem ser relacionados com as instâncias socioeconômicas que dela participam.

Assim, o Relatório Delors deve ser compreendido dentro da perspectiva de busca de um novo ideal de sujeito e cidadão, necessário ao desenvolvimento da sociedade pretendido pela UNESCO. Como já citado no início deste trabalho, os novos modelos de produção em desenvolvimento desde a crise capitalista da década de 70 pressupunha a flexibilização dos processos, modificando paulatinamente a estrutura de trabalho e produção até então existente. Porém, torna-se claro também afirmar que, para operacionalização de todas estas reformas, havia um fator fundamental a ser também modificado: o fator humano. A mão de obra existente precisaria ser readaptada, reeducada para corresponder às ansiedades do novo modelo produtivo. 
Nesse sentido, podemos afirmar que o Relatório é produzido sob a visão de necessidade de um novo trabalhador: flexível, polivalente, conhecedor das tecnologias, dos idiomas, além de ser capaz de tomar decisões e agir de forma autônoma. Evidente que tal autonomia não pode, em hipótese alguma, ser um estorvo ao trabalho em equipe, à cooperação e à parceria entre os sujeitos. Com essa perspectiva, apenas uma conclusão é possível aos membros da Comissão: faz-se necessário um novo modelo de educação que forneça os subsídios necessários á formação desse cidadão/trabalhador.

Todo o Relatório é composto nesse sentido: demonstrar que a educação necessita de novos sentidos e novos olhares para formar o homem para o século XXI. O fundamento do Relatório é justamente a proposta de uma nova educação, ampla, abrangente, e que atenda a todas as necessidades de formação desejadas pelos ideais da UNESCO. A educação seria, ainda, capaz de resolver e explicar as marginalizações, os problemas da sociedade além de todos os demais conflitos e tensões sociais.

Alguns problemas nessas concepções podem ser apontados. Um deles é o conceito de meritocracia implícito na redação do Relatório. Já que a educação tem a responsabilidade de dar ao indivíduo todos os subsídios necessários à sua empregabilidade, cabe a esse indivíduo utilizar tudo isso a seu favor. Portanto, o êxito ou fracasso do indivíduo ficam condicionados ao seu esforço pessoal.

Outrossim, lemos também no Relatório uma sucessiva e (a nosso ver) exagerada responsabilização do indivíduo pelos problemas globais. É o sujeito individual quem deve trabalhar pelo cuidado do "nosso planeta", deve contribuir para a solidariedade e a boa convivência entre as diferentes etnias e sociedades, deve ser reflexivo, ter sentimento de pertencimento loção (à sua sociedade) mas além disso deve ser também um "cidadão do mundo".

Tudo isso nos mostra que os problemas globais são aqui explicados não como fruto das contradições, das diferenças financeiras entre países ricos e pobres e ainda entre ricos e pobres dentro de um mesmo país. Tais contradições são explicadas pela responsabilidade do indivíduo, ou seja, há uma individualização dos problemas globais, como se cada sujeito possuísse nestes o seu quinhão, e fosse então responsável também por uma parte de sua resolução.

Essas perspectivas e concepções se alastraram pelos sistemas educacionais de boa parte do mundo, transformadas em currículos, propostas educacionais e projetos nos diferentes países. Dessa forma, o presente estudo visa contribuir para aprimoramento da leitura de tais propostas, pois compreendemos que, a partir do momento em que conhecemos 
a gênese de determinado documento, somos capazes de identificar essa gênese, quando duplicada ou reproduzida em outros.

As propostas educacionais brasileiras foram também influenciadas pelo Relatório aqui apresentado, sendo que por meio da leitura e compreensão do mesmo podemos ter uma visão mais aprofundada de tais influências. Este trabalho pretende assim contribuir para o conhecimento dos pontos chave do Relatório Delors e assim subsidiar uma leitura mais relevante do mesmo.

\section{REFERÊNCIAS}

DELORS, Jacques (org.). Educação: um tesouro a descobrir. Relatório para a UNESCO da Comissão Internacional sobre Educação para o século XXI. UNESCO: Publicação MEC, 1998. Disponível em: <http://www.pucsp.br/ecopolitica/documentos/cultura_da_paz/docs/Dellors_alli_Relatorio_U nesco_Educacao_tesouro_descobrir_2008.pdf>. Acesso em 12/11/13.

KUENZER, A. Z. Exclusão includente e inclusão excludente: a nova forma de dualidade estrutural que objetiva as novas relações entre educação e trabalho. In: SAVIANI, D.; SANFELICE, J. L.; LOMBARDI, J. C. (Org.). Capitalismo, trabalho e educação. 3. ed. Campinas: Autores Associados, 2005. p. 77-96.

OLIVEIRA, Caroline Mari; MOURA, Kethlen Leite; SILVA,Irizelda Martins de Souza e. Relatório Delors e Relatório Cuéllar: desmistificando a diversidade cultural e a educação na política educacional brasileira a partir da década de 1990. Rev. Visão Global, Joaçaba, v. 13, n. 2, p. 397-418, jul./dez. 2010. Disponível em: <editora.unoesc.edu.br/index.php/visaoglobal/article/download/967/504>. Acesso em 21/11/13.

RIZO, Gabriela. Relatório Delors: a educação para o século XXI. IN: CARVALHO, Elma Júlia Gonçalves de; FAUSTINO, Rosângela Célia. Educação e Diversidade Cultural. Maringá: EDUEM, 2010. p. 55-83. 
VIEIRA, Vanize Aparecida Misael de Andrade; SFORNI, Marta Sueli de Faria. O papel da educação escolar no Relatório Jacques Delors e nos Parâmetros Curriculares Nacionais. s/d. Disponível em: <http://www.nre.seed.pr.gov.br/cianorte/arquivos/File/PEDAGOGAS/CURRICULO/Educaca o_Escolar_Marta_Sforni.pdf>.Acesso em 20/11/13.

\footnotetext{
${ }^{1}$ Doutorando em História pela Universidade Estadual de Maringá (UEM). Mestre em Educação (UEM, 2015). Pedagogo da Universidade Federal do Paraná. Participa dos grupos de pesquisa: Laboratório de Estudos do Império Português (LEIP) e Educação, História e Cultura Brasileira: séculos XVI, XVII e XVIII (DEHSCUBRA). Endereço eletrônico: felipe.afb@ hotmail.com
}

RECEBIDO EM: Setembro de 2016

APROVADO EM: Dezembro de 2016 